\title{
LA METÁFORA Y EL PROTOTIPO. \\ FIGURAS DE LO URBANO EN \\ EL IMAGINARIO SARMIENTINO ${ }^{1}$
}

ADRIÁN GORELIK

(CONICET / Universidad Nacional de Quilmes)

"Como nos sucede no pocas veces, de la fisonomía física de los objetos nos internamos sin sentirlo a andar entrometiéndonos en su contextura moral».

D.F. Sarmiento ${ }^{2}$

«El parque será un modelo presentado al público de lo que el país entero puede ser».

D.F. Sarmiento ${ }^{3}$

1. Es muy difícil dar cuenta en un texto breve del largo y fecundo comercio de Domingo Faustino Sarmiento con los temas urbanos -y uso el término «urbano» por afán de concisión, tratando de comprender en el mismo la amplia gama de cuestiones que interesan a Sarmiento entre la arquitectura, la ciudad y el territorio, desde las grandes infraestructuras hasta los mínimos objetos de uso común, casi como en aquella famosa definición de William Morris en la que «arquitectura" significa el completo entorno de la vida humana con excepción del mero desierto. Contamos, además, con nuevas aproximaciones a las visiones sarmientinas sobre los más diversos aspectos del ambiente construido, que han mostrado

\footnotetext{
${ }^{1}$ Este texto fue presentado en la conferencia «Sarmiento in the Americas: Literature, History, Education and Urban Development Across Two Centuries», Harvard University, 15 de septiembre de 2011.

2 «La villa de Yungay», en: El Mercurio, Valparaíso, 03/04/1842, publicado en Chile. Descripciones

- Viajes - Episodios - Costumbres, Buenos Aires, EUDEBA, 1961, p. 86.

3 «Discurso de inauguración del Parque Tres de Febrero», en: Obras Completas, Buenos Aires, Editorial Luz del Día, 1948-1956, t. XXII, p. 13.
} 
acabadamente su excepcionalidad en el medio intelectual argentino del siglo XIX; como el análisis de Graciela Silvestri sobre la marca pintoresca en la percepción estética de Sarmiento, una clave que le ha permitido resignificar un conjunto de aspectos, desde la comprensión paisajística del sanjuanino hasta los roles ideológicos que él les asignaba a las artes aplicadas; o el de Fernando Aliata sobre la completa trayectoria de Sarmiento en su relación con la cultura material, comenzando por su gusto infantil por los manuales de geografía y su primer aprendizaje de agrimensura, a los 15 años, como ayudante de topógrafo para el trazado del plano de calles de San Juan, y finalizando en sus últimos ańos de vida con la construcción, bajo su dirección, de una casa industrializada isotérmica en Asunción, su modo de presentarles a los paraguayos el ejemplo de una arquitectura capaz de adaptarse al clima local gracias a la tecnología más avanzada ${ }^{4}$. Hace tiempo, por otra parte, me tocó analizar con cierto detalle el itinerario cambiante de las representaciones de Sarmiento sobre Buenos Aires, desde el optimismo que a la distancia le hacía ver en la ciudad-puerto el polo civilizado de la dialéctica espacial argentina, hasta la decepción producida ante la evidencia reiterada de las resistencias al cambio que anidaban en la Buenos Aires realmente existente, cuando luego de largas décadas de prédica reformista, Sarmiento tuvo que admitir el carácter firmemente tradicional de la metrópolis.

Por todo ello, aquí he decidido referirme a una cuestión más general, presente en sordina en todos esos trabajos: las funciones de lo urbano en el pensamiento de Sarmiento. Y propongo que esas funciones pueden estilizarse en dos figuras: la metáfora y el prototipo, bien ejemplificadas en las citas iniciales. Por una parte, la voluntad metafórica que toma la cultura material de un pueblo como recurso interpretativo para comprender su "contextura moral»; las formas de la ciudad, del territorio, de las vestimentas o los objetos, como clave de acceso a la totalidad social histórica. No se trata solamente de un recurso retórico -en una personalidad como Sarmiento, tan pródiga en ellos-, sino del «poder de redescribir la realidad»: los rasgos del paisaje o la ciudad, los deta-

${ }^{4}$ Ver Graciela Silvestri, El lugar común. Una historia de las figuras de paisaje en el Río de la Plata, Buenos Aires, Edhasa, 2011; y Fernando Aliata, «Contemplar y recordar. Sarmiento frente a la arquitectura, el paisaje y la ciudad», en: Adriana Amante (comp.), Sarmiento, volumen en preparación de la colección «Historia crítica de la literatura argentina», dirigida por Noé Jitrik.

${ }^{5}$ Ver Adrián Gorelik, La grilla y el parque. Espacio público y cultura urbana en Buenos Aires 18871936, Buenos Aires, Editorial de la Universidad Nacional de Quilmes, 1998. 
lles arrancados a la apariencia de las cosas son para él huellas privilegiadas que permiten el ejercicio hermenéutico de restituir las conexiones ocultas con que se teje el sentido del mundo ${ }^{6}$.

La metáfora, entonces, por una parte. Y por la otra, el prototipo, el modelo en escala, el experimento programático de nuevos espacios capaces de inventar nuevos habitantes, es decir, de modelar nuevos hábitos y crear una completa cultura nueva. Aquí la ciudad, la arquitectura, el paisaje entran en el imaginario sarmientino como máquinas productoras de costumbres cívicas, dispositivos para inocular, a través de rutinas inadvertidas, modos virtuosos de vida colectiva.

2. La lectura del detalle como clave hermenéutica de la totalidad no se restringe, por supuesto, en la economía argumental de Sarmiento, a los temas de la cultura material; es un recurso permanente que ha sido señalado como un rasgo consti- tutivo de su modo peculiarmente romántico de pensar -y explicar- el mundo. Tulio Halperin ya ha mostrado el rol del fragmento en los cuadros descriptivos que componen la narrativa de Sarmiento, su función enunciativa de vastas unidades de sentido: la anécdota del encuentro entre el joven Facundo y el tigre como síntesis de todo un horizonte geográfico y espiritual que Sarmiento resume con la palabra barbarie; el cuadro de los escolares cantando el himno en la Plaza de la Victoria como presencia activa -no símbolo- de la libertad y el progreso; y ha explicado la encrucijada de estímulos que produjo ese tipo de pensamiento figurativo: la literatura eclesiástica de la infancia y la literatura romántica de la juventud, atravesadas por nociones arraigadas del universo clásico e ilustrado ${ }^{7}$. Y Carlos Altamirano ha sumado a ello la necesaria cualidad visual de un procedimiento que busca dar apariencia sensible al pensamiento: «como si Sarmiento respondiera, in actu y permanentemente a la pregunta:

\footnotetext{
6 Llamo «metáfora» a los usos retóricos que Sarmiento hace de las imágenes del mundo construido, tomando un sentido amplio de la noción de metáfora, de acuerdo a Ricoeur, de quien es la frase entrecomillada: la metáfora como el proceso por el cual el discurso libra el poder de ciertas ficciones de redescribir la realidad. Ver Paul Ricoeur, La metáfora viva (1975), Buenos Aires, Ediciones Megalópolis, 1977, especialmente los capítulos 6, 7 y 8 sobre las funciones hermenéuticas de la metáfora.

7 Ver de Tulio Halperin Donghi, «Facundo y el historicismo romántico» (1955), en: Ensayos de historiografía, Buenos Aires, Ediciones El Cielo por Asalto, 1996; y su «Prólogo» a Domingo F. Sarmiento, Campaña en el Ejército Grande (1958), Buenos Aires, Editorial de la Universidad Nacional de Quilmes, 1997.
} 
¿qué escena, qué relato, qué individuo, qué hecho, puede dar figura a la idea?» ${ }^{8}$.

Pero de entre todas las figuras que el sistema de pensamiento de Sarmiento ofrece una y otra vez, puede decirse que aquellas que provienen del mundo físico tienen una presencia decisiva. Por varias razones, entre las que sobresale el peso de un imaginario clásico que explica al hombre y su cultura a partir de su condición geográfica. En el siglo XIX ese imaginario había recorrido un largo camino, entreverado ya de matices ilustrados y románticos, como ejemplifican los nombres de Montesquieu y Humboldt, y había nutrido un conjunto de disciplinas de fuerte impacto en Sarmiento, como la geografía y la historia'. Nombres y disciplinas que también tejían la «red textual» que Adolfo Prieto vio tenderse entre las primeras descripciones de Argentina de los viajeros ingleses y el surgimiento de la literatura local ${ }^{10}$.

De ese equipamiento intelectual surge, como se sabe, tanto la fuerza metonímica de la palabra «desierto», como la igualación entre los binomios civilización / barbarie y ciudad / campo. Pero el rol de la ciudad en este sistema figurativo tiene una importancia específica, que no deriva simplemente de su capacidad demostrativa dentro del polo civilizatorio. Así lo muestra el ejemplo de Córdoba, que una y otra vez equivaldrá para Sarmiento a un tipo de civilización muy particular, opuesta al de Buenos Aires: el mundo colonial, el oscurantismo español, la Edad Media, la opresión religiosa sobre las costumbres y las ideas, un conjunto de significados que cabe en la figura del "claustro" -una figura arquitectónica para hacer sensibles los contenidos de una figura urbana, que hacían sensibles los contenidos..., y así siguiendo, como una muñeca rusa. La eficacia narrativa con que Sarmiento cifra en una serie de rasgos paisajísticos de Córdoba -la hondonada y las barrancas, los campanarios, la cañada, el damero, la posición central de la ciudad en el viejo país colonial-, las claves de un entero universo de sentido, no deja de sorprendernos hasta hoy. Córdoba seguiría sirviendo de espejo invertido para Buenos Aires durante mucho tiempo, aunque, como mostró recientemente Ana Clarisa Agüero, también es evidente que el interés demostrado una y otra vez en aquella

\footnotetext{
${ }^{8}$ Carlos Altamirano, «Introducción» a Domingo F. Sarmiento, Facundo o Civilización y Barbarie, Buenos Aires, Colección Austral, Espasa Calpe, 1993, p. 35.

9 Una excelente historia de las ideas acerca de la relación entre el organismo y el medio hasta llegar al romanticismo, donde ocurre su apogeo, en Georges Canguilhem, «L'essere vivente e il suo ambiente» (1952), en: La conoscenza della vita, Bologna, II Mulino, 1976.

${ }^{10}$ Adolfo Prieto, Los viajeros ingleses y la emergencia de la literatura argentina, Buenos Aires, Sudamericana, 1996.
} 
ciudad está indicando que Sarmiento le asignaba un lugar importante en el diseño de un país policéntrico -la idea, sugerida en Recuerdos de provincia, de una red de ciudades en condiciones de aportar diversas fuentes culturales al país moderno que debía formarse ${ }^{11}$.

Si el imaginario geográfico y ambiental reconoce estímulos variados, esta centralidad de lo urbano en el sistema metafórico de Sarmiento tiene una coloración ya propiamente romántica: la idea de ciudad como obra de arte colectiva, ejemplo máximo de la unidad cultural que expresa toda forma de vida histórica. Es una idea organicista, que se forjó en la recuperación decimonónica del Medioevo europeo: ante el espectáculo devastador de la nueva barbarie introducida por la ciudad industrial, las pequeñas ciudades históricas aparecieron como summa cultural de una comunidad armónica, manifestación original de un pueblo situado y encarnación material de sus instituciones democráticas. Y por eso Sarmiento está tan preparado para ver en cada rasgo del equipamiento material de una comunidad urbana, el signo más abarcativo de una civilización definida; y así las «calles estrechas y sucias» de Buenos Aires podrán explicar las «suciedades en el alma» de su pueblo y, más allá, «las elecciones de los maulas ${ }^{12}$. El sistema metafórico toma el mundo material como una cadena de signos que se remiten unos a otros: ¿hay mejor testigo de las ilusiones perdidas de Mayo que los despojos del paseo público donado por los Jofré a San Juan, cuya pirámide, que supo ser centro monumental, ha quedado con su punta quebrada como «tumba de la revolución, muerta en la infancia, ruina ya a los treinta años de erigida»? ${ }^{13}$ ¿Y hay mejor test comparativo de formas civilizatorias que el mango de la escoba usado en los Estados Unidos frente a la «escobita de palma» que se usa en España, con las correspondientes posturas corporales a las que llevan, una erguida dignamente, la otra «doblando el espinazo para alcanzar el suelo»? ${ }^{14}$.

${ }^{11}$ Ver Ana Clarisa Agüero, Local / nacional. Córdoba: cultura urbana, contacto con Buenos Aires y lugares relativos en el mapa cultural argentino (1880-1918), tesis de doctorado, Facultad de Filosofía y Humanidades, Universidad Nacional de Córdoba, marzo de 2010, mimeo; especialmente su primer capítulo, «Córdoba en el país». Sobre la oposición entre Córdoba y Buenos Aires, ver también Ana María Barrenechea, «Sarmiento and the Buenos Aires/Córdoba Duality», en: Tulio Halperin Donghi, I. Jaksic, J. Kirkpatrick y F. Masiello (edits.), Sarmiento Author of a nation, California, University of California Press, 1994.

12 «El Parque de La Plata», 07/11/1882, en: Obras Completas, op. cit., t. XLII, p. 89.

${ }^{13}$ Recuerdos de provincia, Buenos Aires, EUDEBA, 1960, pp. 33-34.

${ }^{14}$ Viajes por Europa, África y América, 1845-1847 y Diario de gastos, edición crítica de Javier Fernández, Colección Archivos, Buenos Aires, Fondo de Cultura Económica, 1993, p. 164. 
3. Pero esa última frase nos lleva a los Viajes, y especialmente a los Estados Unidos. Por cierto, el relato de viajes bien puede considerarse la apoteosis del sistema metafórico sarmientino: si todo relato de viajes funciona con el combustible de la comparación, las necesidades descriptivas del género no hicieron más que potenciar el talento figurativo del sanjuanino. Sin embargo, es en el capítulo norteamericano de su viaje donde también comienza a advertir las potencialidades proyectuales de la arquitectura y la ciudad.

Así que junto al modo, digamos, analógico y descriptivo, de pensar el vínculo entre ciudad y sociedad, Sarmiento va a comenzar a desarrollar aquella otra modalidad, programática, que va a caracterizar de aquí en más sus figuraciones para la transformación de la sociedad argentina. El impacto de los Estados Unidos en esta forma de pensar el mundo material aparece desde el comienzo subrayado por él mismo; por ejemplo, cuando proponga en 1853 uno de sus primeros prototipos, y posiblemente el más original, la Quinta Normal -Sarmiento estaba nuevamente en Santiago de Chile, exiliado ahora por sus conflictos con Urquiza, pero el debate abierto sobre el futuro del país habilita- ba su exaltación proyectual. El nombre para este prototipo lo tomó de la Quinta Normal de Agricultura, que había sido creada en Santiago hacía una década para la enseñanza y la experimentación agronómica y estaba entonces en pleno proceso de expansión, con el trazado de un parque, jardín botánico e invernadero ${ }^{15}$. Pero si la fuente de inspiración directa es muy clara, y si a través de ella se filtra la marca pedagógica francesa, el prototipo de Sarmiento busca ser algo más: una máquina de traspaso de una sociedad tradicional a otra moderna, de acuerdo al modelo de los Estados Unidos. Lo que Sarmiento propone es reunir en un único dispositivo urbano-territorial un conjunto más vasto de instituciones -no sólo centros agrícolas experimentales, viveros y parques, como en el modelo chileno, sino también escuelas de maestros, casas de reforma, postas de vacuna, correos, sociedades de fomento de la producción, etc.-; instituciones que él ha conocido dispersas en muchas partes del mundo, pero que remiten, como una semilla al árbol, a los Estados Unidos, aquel «inmenso laboratorio de la riqueza» en el que no hace falta una Quinta Normal sostenida por el gobierno, "porque el país entero

${ }^{15}$ Ver Luis Suda, La Quinta Normal y la enseñanza de la agricultura en Chile, Santiago, Imprenta del Ferrocarril, 1860. 
es una Quinta Normal $»^{16}$. Y justamente como una semilla de un árbol robusto transplantada a un campo yermo, así Sarmiento imagina la acción regeneradora de este prototipo situado estratégicamente en diversos puntos del país, modelo en escala creado por el Estado para el establecimiento de las condiciones que hicieran posible la expansión de sus efectos modernizadores en toda la sociedad.

También desde Chile había propuesto su otro gran prototipo, posiblemente el más exitoso: el edificio escolar como parte sustancial de un plan de educación, ya que, como pudo constatar en los Estados Unidos, una arquitectura escolar especializada podía hacer funcionar a la escuela no sólo como una institución libresca, sino como un laboratorio práctico, capaz de crear de la nada nuevas disposiciones ciudadanas $^{17}$. El optimismo casi benthamiano en la capacidad reguladora del espacio que muestra Sarmiento cuando formula estos prototipos, lo aplicará el resto de sus días a las más variadas empresas, y explica, en buena medida, la importancia excepcional que le dio a la reforma urbana y territorial. Sólo por recordar los emprendimientos más conocidos, podemos mencionar los proyectos durante su concejalía en Buenos Aires; el plan de colonización en Chivilcoy, durante su senaduría en el Estado de Buenos Aires; su campaña periodística hacia los mismos ańos para desarrollar el Delta del Paraná; la creación del parque de Palermo durante su presidencia; la propuesta de un centro recreativo y productivo en la laguna de Junín (el «Mar Sarmiento»), a la vejez.

4. Hemos reconocido ya las dos formas en que Sarmiento entiende las relaciones entre ciudad y sociedad, y a esta altura del razonamiento no se escapa que, llevadas a sus últimas implicancias, reconocen fuertes contradicciones, como si respondieran a paradigmas enfrentados de comprensión del mundo. Tanto es así, que podríamos ver las proyecciones hacia el siglo XX de ambas modalidades en el pesimismo metafísico de Martínez Estrada y el opti-

16 Domingo F. Sarmiento, «Quinta Normal de Aclimatación de plantas en Mendoza», 19/11/1853, en: Obras Completas, op. cit., t. X, pp. 214. El desarrollo más articulado de esta idea, lo presentó en su Plan combinado de Educación común, silvicultura e industria pastoril, aplicable al Estado de Buenos Aires, editado en Santiago en 1855 (en Obras Completas, op. cit., t. XXIII). Sarmiento incentivó al gobierno mendocino desde Chile para la creación de una Quinta Normal; luego creó él mismo otra, durante su gobernación en San Juan en 1862; y en esta misma idea fundamentó sus primeros proyectos para Palermo.

${ }^{17}$ Ver De la educación popular (1849), en: Obras Completas, op. cit., t. XI. 
mismo blindado de los planificadores desarrollistas, respectivamente. Es que el sistema metafórico tiende al determinismo, porque el juego interpretativo sobre la red de signos urbanos y territoriales se sostiene en una confianza circular: el hombre es producto del medio, y la obra colectiva que levanta a lo largo de generaciones le da forma cultural a esa dependencia y la reproduce. En cambio, la visión de la ciudad y la arquitectura como sostén de experimentos proyectuales muestra el grado máximo de confianza en la capacidad de la acción humana para promover -e incluso garantizar- el cambio.

Sería sin embargo un error creer que Sarmiento andaba divido entre ambos paradigmas, como una especie de Jekyll \& Hyde, o que cada una de esas formas de ver constituyen etapas sucesivas de su pensamiento, cuya progresión se habría producido gracias a la iluminación norteamericana. Y quizás colocar el foco en sus representaciones sobre la ciudad y la arquitectura permita entender de modo más matizado esta dialéctica de la mirada en Sarmiento, que conecta con dimensiones más amplias de su pensamiento; esa combinación de pensamiento ilustrado y romántico con incrustaciones de forma- ción clásica y religiosa, en la que no parece productivo identificar compartimentos estancos o etapas diáfanas. Lo primero que llama la atención, en ese sentido, es que Sarmiento continuó utilizando ambos registros: para él, la ciudad (o el territorio) moldea a la sociedad que la habita pero, justamente por eso, puede cambiarla. Y fue el impacto de los Estados Unidos, en efecto, lo que le permitió no realizar el pasaje de uno a otro modelo, sino encontrar el nexo entre ambos ${ }^{18}$.

La experiencia norteamericana habilita a Sarmiento a poner el sistema metafórico a disposición de su imaginación proyectual, porque todos los signos visibles de esa cultura urbana se le ofrecen como piezas inteligentes de un mecanismo perfecto, cada una de las cuales lleva grabado el manual de instrucciones con el cual producirlo. Como señaló Aliata, «la vestimenta, la casa, los enseres domésticos de los norteamericanos le parecen [a Sarmiento] una demostración concreta de la igualdad lograda y una explicación precisa acerca del modo en que este proceso se realiza» ${ }^{19}$. Es como si viera la completa civilización norteamericana como un Meccano, pasible de ser trasladado por piezas al sur. El punto de contacto po-

\footnotetext{
${ }^{18}$ En un trabajo por cierto notable, Elías Palti ha establecido en el viaje norteamericano un quiebre radical en las matrices del pensamiento de Sarmiento; creo que el análisis de sus representaciones urbanas y territoriales permite poner tal quiebre en cuestión. Ver Elías Palti, Sarmiento, una aventura intelectual, Buenos Aires, Instituto de Historia Argentina y Americana Dr. Emilio Ravignani, FFyL-UBA, 1991.

19 Fernando Aliata, «Contemplar y recordar...», op. cit.
} 
tencial entre el norte y el sur americanos para hacerlo posible sería una carencia vuelta virtud: la ausencia del pasado que lastraba a Europa. Esa ausencia explicaba la expansión de una civilización tan homogénea en el amplísimo territorio norteamericano: la uniformidad de la cultura material norteamericana asombra y deleita a Sarmiento no sólo porque advierte el hilo que la conecta con la igualdad social y política, sino porque está convencido de que ese hilo tiene doble mano, y que la uniformidad material es más accesible que la igualdad cívica para ser implantada ex nibilo en la Argentina. Ese es el momento en que la idea de "desierto" reelabora su faz determinista desde una faz vanguardista: ahora es el lugar donde lo nuevo podrá emerger sin obstáculos.

5. Pero así como parece sencillo identificar los cambios producidos por el viaje, sorprende la tenacidad de ciertas convicciones. Más aún sabiendo la importancia que tuvo para Sarmiento ese primer viaje, cuando pudo confrontar de visu la enciclopedia urbana que había comenzado a organizar con sus salvajes lecturas a distancia. Si todos los que nacimos «lejos» hemos vivido alguna vez ese momento epifánico y podemos dar cuenta de su importancia en nuestra formación intelectual, es muy fácil imaginar cuánto más importante habrá sido para Sarmiento, justamente por su pensamiento figurativo: la posibilidad de poner las imágenes ciertas a sus ideas preexistentes, con todo lo que eso supone de ajuste, de contraste, de reemplazo, de reinvención -esa es otra cosa fascinante de los Viajes: a diferencia del viajero profesional, Sarmiento relata un aprendizaje. Por eso mismo, insisto, junto a todo lo que el viaje cambió en él, sobresale la fuerza de las posiciones que ya llevaba consigo.

Por ejemplo, la escasa sintonía que muestra Sarmiento con las visiones románticas de la ciudad realmente existente -es decir, con el rechazo de la gran ciudad «como vicio» que tan bien caracterizó Schorske, cuyo resultado era la nueva pasión por las bellezas melancólicas de todo rincón urbano que hubiera sido dejado de lado por el progreso ${ }^{20}$. Es evidente que Sarmiento viajó prevenido contra esta tendencia nostálgica: «No creáis nada de cuanto dicen Chateaubriand y otros de las bellezas de la mezquita de Córdoba [...] Aquí no hay nada ${ }^{21}$. Sarmiento piensa la ciudad como la política: hay que entender y valorar el pasado, pero en tanto complemento

${ }^{20}$ Ver Carl Schorske, «La idea de la ciudad en el pensamiento europeo: de Voltaire a Spengler», en: Pensar la historia. Ensayos sobre la transición a la modernidad, Buenos Aires, Taurus, 1998.

${ }^{21}$ Viajes, op. cit., p. 162. 
necesario del proceso histórico en curso; por el contrario, el exceso de revisionismo romántico lleva a la restauración, como ocurre en Francia con Luis Felipe («el modelo de todos los bastardos edificios que se están levantando en América») ${ }^{22}$. Por eso celebra en París la apertura de una calle «magnífica» que elimina «aquellas pocilgas y vericuetos donde los Misterios comienzan $»^{23}$. Y aquí no puede ser más claro Sarmiento acerca de la división tajante que establece entre el mundo de la literatura y el de la realidad, en el que las ensoñaciones románticas pueden volverse peligrosas: así, Burgos, aun si su encanto nocturno es indudable, «de día es un pobre montón de ruinas habitadas por un pueblo cuyo aspecto es todo lo que se quiera, menos poético» ${ }^{24}$.

Córdoba, Burgos..., pero no es sólo España -ni toda España: Barcelona es diferente, «es europea» y su Rambla «asemeja un boulevard $»^{25}$. Por ejemplo, Roma es «desapacible y triste» y su larga historia "de gloria y miserias agobia demasiado ya los hombros de esta ciudad, sobre la cual se arrastra pesadamente el día sin el estrépito de las artes, la locomoción y el bullicio de las otras capitales ${ }^{26}$. Locomoción, bullicio, el ritmo acelerado y peligroso del boulevard en contra de «la quietud de las calles de [las] ciudades americanas»: eso es lo que Sarmiento estaba preparado para encontrar, y siguió disfrutando aun después de haberlo conocido, en París o en Nueva York ${ }^{27}$.

Y esta es, claro, la otra cuestión que lo separa del romanticismo: la actitud inusual de celebración de la ciudad moderna como vía regia a la modernización social. Por cierto, ya Tulio Halperin ha señalado con justeza que Sarmiento nunca abriga «el romanticismo de la desesperación o la duda ${ }^{28}$. Pero casi todos los escritores que él admira, aunque tampoco cultivaran esos abismos románticos, eran muy claros en la condena del nuevo espectáculo que ofrecían las grandes ciudades. Como Tocqueville, que hizo descripciones más amargas acerca del progreso de la civilización en Manchester que las célebres de Engels sobre los tugurios de esa ciudad;

\footnotetext{
${ }^{22}$ La referencia a la relación entre revisionismo romántico y restauración en Francia, en Viajes, pp. 94-96. Sarmiento mantendrá siempre la misma posición respecto de la restauración en los temas urbanos, colocándose a favor de la renovación.

${ }^{23}$ Idem, p. 99.

24 Idem, p. 135.

25 Idem, p. 167.

${ }^{26}$ Idem, p. 209.

${ }^{27}$ Idem, p. 99.

${ }^{28}$ Tulio Halperin Donghi, «Facundo y el historicismo romántico», op. cit., p. 21.
} 
o Fenimore Cooper, cuyas novelas escenificaron el drama cultural norteamericano de la naturaleza virtuosa amenazada por la civilización urbana. $Y$ aunque no todos llegaran a esos grados de condena de la ciudad moderna, es claro que el clima cultural a mediados del siglo XIX, tanto en Europa como en los Estados Unidos, era de desconfianza hacia ella: como señaló Nisbet, la ciudad era el modelo para todas las proposiciones sobre la desorganización, la alienación y el caos social que estaban componiendo el nuevo corpus sociológi$\mathrm{Co}^{29}$. Lo curioso, entonces, es que donde los intelectuales de su tiempo veían un problema, Sarmiento se empeñara en encontrar la solución. Porque nunca rompió la alianza estrecha que estableció de joven entre ciudad y civilización moderna.

Es cierto que desde su llegada a Europa Sarmiento ha sido impactado por «esa triste mezcla de grandeza y abyección, de saber y embrutecimiento a la vez» que encuentra apenas desembarca en Le Havre; pero a diferencia del pensamiento social contemporáneo, Sarmiento jamás hará responsable de esas dilaceraciones de la modernidad a la ciudad moderna. Por el contrario, toda modernización de la ciudad es alabada como un indicio de modernización social. Los dos escándalos que Sarmiento no se cansa de denunciar en su travesía europea son la modernización sin inclusión y la falta de modernización. Y no es la ciudad, sino el viejo sistema de privilegios sociales y políticos del Antiguo Régimen que sobrevive transfigurado en el nuevo espacio abierto por la doble revolución, su causante.

6. Por fin, quizás ahora se pueda ponderar mejor un tema muy tratado por la bibliografía sobre Sarmiento: su deslumbramiento por la aldea norteamericana. Es notorio que encontró en la aldea un microcosmos perfecto, la unidad más pequeña en que el mecanismo de la sociedad norteamericana se encuentra ya articulado en una forma completa y compleja: «la aldea norteamericana es ya todo el estado, en su gobierno civil, su prensa, sus escuelas, sus bancos, su municipalidad, su censo, su espíritu y su apariencia ${ }^{30}$. Es también interesante pensar que tal reencantamiento de la aldea (como señaló Halperin: el descubrimiento de una nación en que hasta la aldea más pobre funciona como confirmación de los más altos valores que esa nación sostiene, y no como su negación, cosa que ocurre para Sarmiento tanto en Chile como en Francia), le permitió revalorar al sanjuanino su propia cultura aldeana, así como

\footnotetext{
${ }^{29}$ Robert Nisbet, La formación del pensamiento sociológico, Buenos Aires, Amorrortu, 1996.

30 Viajes, op. cit., p. 297.
} 
el lugar de estas ciudades menores en la formación nacional. $\mathrm{Y}$ asimismo es muy sencillo entender que la aldea se le apareciera como el prototipo perfecto para el proceso de colonización agrícola que quería ver realizado en la Argentina. Todo eso es indudable. Pero justamente porque nota que la aldea norteamericana es ya "todo el estado», no hay contraposición alguna para Sarmiento entre ella y la gran ciudad; las dos forman más bien las diversas y necesarias gradaciones de un sistema social articulado ${ }^{31}$.

Es posible apreciar mejor la singularidad de la posición de Sarmiento en este tema si se la compara con el enfoque que Tocqueville le había dado, ya que él sí había contrapuesto, en acuerdo con el pensamiento social de su tiempo, la aldea norteamericana a la gran ciudad. En efecto, en el primer tomo de la Democracia en América, Tocqueville había alertado acerca de la "amenaza» que significaban para el porvenir de Norteamérica las grandes ciudades industriales, con su populacho «más peligroso que el de Europa» (se refería a las dos ciudades que en 1830 podían considerarse grandes, Nueva York, con 200.000 habitantes, y Filadelfia, con 160.000). De hecho, Tocqueville explicó el éxito del experimento republicano en los Estados Unidos tanto en la ausencia de una gran ciudad capital, como en el hecho de que las grandes ciudades existentes no habían tenido hasta entonces ninguna influencia en la vida del resto del país, la Norteamérica profunda, rural y aldeana ${ }^{32}$. Sarmiento pudo haber tomado de aquí el juicio adverso sobre los inmigrantes europeos en las ciudades norteamericanas, «elemento de barbarie, quién lo creyera!», «levadura de corrupción que se introduce anualmente en la masa de la sangre de aquella nación tan antiguamente educada en las prácticas de la libertad $\|^{33}$. Pero no convirtió ese juicio sobre la inmigración en un diagnóstico sobre la gran ciudad.

Esto queda demostrado in extenso en toda su larga prédica urbana, como cuando en el entusiasmo autonomista proponía que Buenos Aires se convirtiera en la Nueva York del sur, «con su medio millón de habitantes» y su rol rector en la nación; o como las múltiples veces que festejó a Rosario como la más norteamericana

${ }^{31}$ William Katra ha sostenido la hipótesis exactamente contraria, a saber, que desde el viaje norteamericano Sarmiento ya «no defendió a la ciudad como fuente del progreso, sino a la aldea»; ver W. H. Katra, «Sarmiento en los Estados Unidos», en: Viajes, edición citada, p. 902.

32 Alexis de Tocqueville, La democracia en América, t. 1 (1830), Madrid, Sarpe, 1984, p. 277 y especialmente la remisión a una larga nota en pp. 426-427.

${ }^{33}$ Viajes, op. cit., p. 343. 
de las ciudades argentinas por su fabuloso progreso («sólo Chicago y Búfalo han marchado a este paso»), no precisamente porque la considerara una aldea ${ }^{34}$. El mismo optimismo urbano que se encuentra en su propuesta institucional más articulada para la construcción de la nación, Argirópolis. En verdad, es ya llamativo que el proyecto completo lleve como título el nombre de la ciudad capital que Sarmiento propone para la nueva federación que habría de formarse; si bien es cierto que el de la capital era uno de los nudos principales a destrabar en el proceso que iba a abrirse en el país a la caída de Rosas (y también que Sarmiento estaba muy orgulloso del ingenio político de su solución, que proponía como tal a la isla Martín García), no lo es menos que esta propuesta coloca como centro de gravedad de todo su sistema a una gran ciudad capital, y a la manera de las utopías clásicas, lo identifica con su nombre. De hecho, Sarmiento siente la necesidad de defenderse anticipadamente de las críticas que le podrían señalar el escaso tamaño de la isla Martín García para la capital que imagina; y no lo hace advirtiendo que una gran ciudad capital sería una amenaza para la república federal, como podría haber hecho inspirándose en $\mathrm{La}$ democracia en América -y no hay que olvidar que Argirópolis está escrita en el halo del impacto del viaje por los Estados Unidos al que el libro de Tocqueville hizo de guía-; por el contrario, Sarmiento explica que ese escaso tamaño no va a impedir el desarrollo de la gran capital que propone, sino que va a obligar a concentrar la ciudad y densificarla en altura, solución urbana que considera adecuada no sólo para su capital imaginaria, sino para todas las ciudades de la América española, cuya «superficie desmesurada» las desparrama irracionalmente por la llanura ${ }^{35}$. Quizás también en este tema Sarmiento estuviera adaptando arraigados conceptos que provenían de la experiencia colonial, la evidencia de que todo un sistema civilizatorio podía implantarse a través de una red de ciudades; pero en todo caso, esos conceptos le permitían empalmar ahora con un imaginario de la ciudad moderna nada moderado.

7. A través de sus hallazgos metafóricos, Sarmiento produjo los principales tópicos

\footnotetext{
${ }^{34}$ Hay innumerables citas de ese estilo en los escritos de Sarmiento; pongo solamente un ejemplo de cada una: de la comparación con Nueva York, su discurso de asunción como diputado a la Legislatura de Buenos Aires, en 1854, Obras Completas, op. cit., t. XVI, pp. 137; del elogio a Rosario, su artículo «La expedición a Tucumán», de 1876, en: Obras Completas, op. cit., t. XLII, pp. 23-24.

${ }^{35}$ Ver Domingo F. Sarmiento, Argirópolis, Buenos Aires, La Cultura Argentina, 1916 (con introducción de Ernesto Quesada), pp. 134-135.
} 
con que la ciudad y el ambiente construido pudieron ser pensados en su relación con la sociedad, la política y la cultura en la Argentina moderna; a través de sus prototipos, introdujo una visión constructivista de esa relación ciudad/sociedad que abonaría todos los grandes momentos desarrollistas del país. Se trata, como vimos, de paradigmas opuestos, pero que en Sarmiento encontraron un espacio de mutua potenciación. Y la importancia del impacto de las ideas de Sarmiento no decrece cuando notamos que casi ninguna de sus propuestas llegó a buen puerto (al menos no al puerto que él imaginaba). En este sentido, vale la pena señalar que la conocida excentricidad de Sarmiento respecto de la cultura establecida en
Argentina -y especialmente, en Buenos Aires-, alcanza en estos temas su máxima expresión: su insistencia en los patrones urbanos y territoriales anglosajones frente a la sólida tradición ingenieril continental (napoleónica) que dominó todo el XIX argentino (ese Departamento Topográfico que para Sarmiento tenía mucho más de «topo» que de "gráfico»), es tan extravagante como su gusto pintoresquista frente a la voluntad de clasicismo de la élite porteña en su ambición de definirse como tal en el último tercio del siglo. Y, sin embargo, esas metáforas y esos prototipos lograron ampliar de modo excepcional el horizonte de lo que la cultura argentina podía pensar sobre su propia constitución material, y seguir pensando hasta hoy. 